Check for updates

Cite this: RSC Adv., 2019, 9, 35059

Received 17th July 2019

Accepted 16th October 2019

DOI: $10.1039 / c 9 r a 05490 a$

rsc.li/rsc-advances

\title{
Multifunctional lubricant additive based on difluoroboron derivatives of a diphenylamine antioxidant $\uparrow$
}

\begin{abstract}
Shengpei Wang, ${ }^{\text {ab }}$ Shasha Yu, (D)*a Jianxiang Feng ${ }^{a}$ and Shenggao Liu*a
A metal-free and phosphorus-free novel multifunctional additive (E)-4-((3-(tert-butyl)-2-((difluoroboranyl) oxy)-5-((octylthio)methyl)benzylidene)amino)- $N$-phenylaniline (difluoroboron derivative 4a) was synthesized and characterized. The results show that its antioxidation and tribological properties are better than those of base oil, diphenylamine and zinc dialkyldithiophosphate (ZDDP), and it can also increase the extreme pressure performance of the base oil. In addition, it can be found that the diphenylamine functional group, boron and fluorine are the main contributors to the excellent antioxidation and antiwear properties of difluoroboron derivative $4 \mathrm{a}$, respectively. Finally, the results of $\mathrm{X}$-ray photoelectron spectroscopy on the worn surfaces reveal that $\mathrm{B}_{2} \mathrm{O}_{3}, \mathrm{Fe}_{2} \mathrm{O}_{3}$, a N-containing organic compound and iron fluoride comprise the boundary films, which effectively improve the difluoroboron derivative 4a's antiwear properties.
\end{abstract}

\section{Introduction}

In order to reduce wear and friction and prolong the service life of mechanical systems, lubricants are widely used in industry. ${ }^{1}$ Multifunctional lubricant additives are a kind of lubricant additive with more than one property. ${ }^{2}$ Zinc dialkyldithiophosphate (ZDDP) is the most widely used multifunctional lubricant additive with excellent antioxidation, anticorrosive and antiwear abilities. ${ }^{3}$ However, SAPS (Sulfated ash, Phosphorous and Sulfur) of ZDDP are prone to reduce the life of automotive exhaust gas-treatment systems. In order to improve the compatibility of the emission system, strict laws restrict the use of ZDDP. ${ }^{4,5}$ For example, ILSAC GF-5 standards limit the phosphorous and sulfur contents in vehicle engine oil below $0.08 \%$ and $0.50 \%$, respectively. ${ }^{6}$ Therefore, it is a progressive trend to develop new non-SAPS or low SAPS multifunctional lubricant additives without reducing the antioxidation and antiwear capabilities. ${ }^{7-9}$

Several kinds of compounds with low or zero SAPS has been studied, such as heterocyclic compounds, ${ }^{10-12}$ boron containing compounds, ${ }^{13-15}$ ionic liquids ${ }^{16,17}$ and nanoparticles. ${ }^{18-20}$ It is well known that antioxidants can improve the oxidation stability of lubricant. Modification of antioxidants with the active elements of $\mathrm{B}, \mathrm{S}$ and $\mathrm{P}$ is a research hotspot of

${ }^{a}$ Ningbo Institute of Materials Technology and Engineering, Chinese Academy of Sciences, No. 1219, Zhongguan West Road, Ningbo, Zhejiang, 315201, P. R. China. E-mail: rukawayss@hotmail.com; sliu@nimte.ac.cn

${ }^{b}$ University of Chinese Academy of Sciences, Beijing, 100049, P. R. China

$\dagger$ Electronic supplementary information (ESI) available. See DOI: 10.1039/c9ra05490a multifunctional lubricant additives, such as multifunctional Schiff bases (e.g. CySBE and TrBzEd) ${ }^{21-24}$ high performance multifunctional additive BHMT, ${ }^{10} \mathrm{~N}$-containing borate ester BMEB (ref. 25) and imidazolium-based ionic liquids (e.g. (BHT1) $\left.\mathbf{M I M B F}_{4}\right) \cdot{ }^{26,27}$ As shown in Scheme 1 , all the above works focus on the modification of hindered phenolic antioxidants. Diphenylamine has been widely used as the main free radical scavenger, but there are few multifunctional additives synthesized by modifying diphenylamine. Weimin Liu and co-authors have synthesized some novel multifunctional additives P-N compounds (Scheme 1) with better tribological behaviors than ZDDP. ${ }^{2}$ However, due to the removal of active $\mathrm{H}$ atom in diphenylamine, their antioxidation capacity is not significantly better than ZDDP. So, it is meaningful and challenging to synthesize a new high performance and low or zero SAPS multifunctional additive by modifying diphenylamine.

Recently, we have synthesized a series of Schiff base bridged phenolic diphenylamine (SPD, Scheme 1) antioxidants, which have better antioxidation performance than commercial antioxidants. ${ }^{28,29}$ It is interesting that synergistic antioxidation effect was found when combined with borate polyisobutylene succinimide (PIBSI) dispersant. ${ }^{28}$ Furthermore, it has been reported that the antiwear properties of lubricating oils can be greatly improved by the mixture or chemical synthesis of the Schiff bases (such as AAPx in Scheme 1) and borate esters. ${ }^{30-32}$ Thus, based on the great synergistic effect between Schiff base and borate, we designed and synthesized a new kind of coordinately saturated boron complex by combining $\mathrm{N}^{\wedge} \mathrm{O}$-bidentate ligands in SPD with $\mathrm{B}(\mathrm{III})$ fragment. Unlike the reported borate ester additives, $\mathrm{BF}_{2}$ was selected as the $\mathrm{B}(\mathrm{III})$ fragment due to the antiwear performance of fluorine containing compounds, ${ }^{26,33}$ facile synthesis and stable 


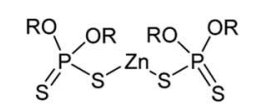

ZDDP

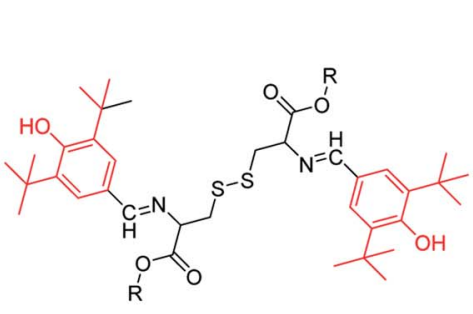

CySBE

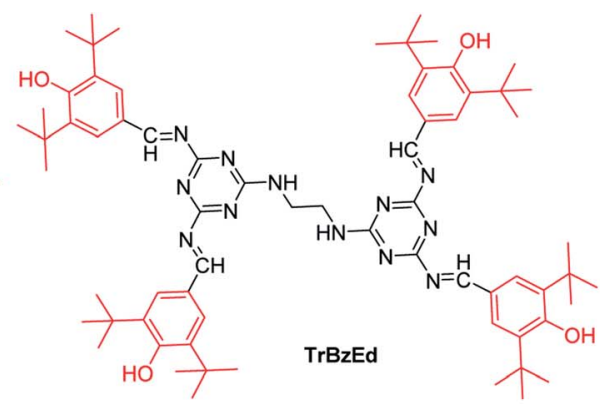

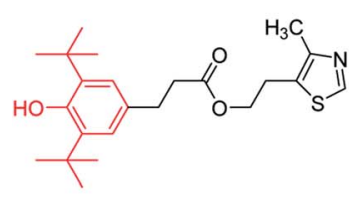

BHMT

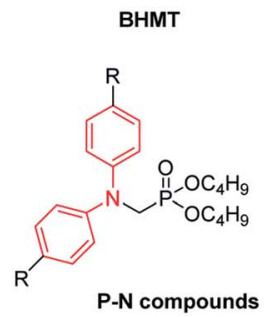

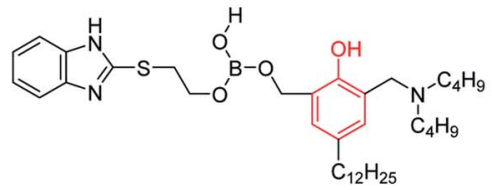

BMEB

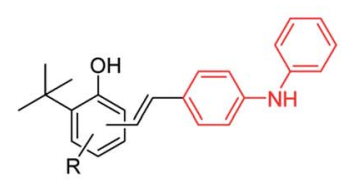

SPD

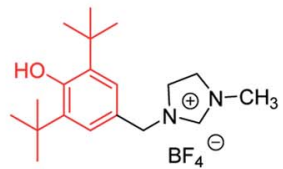

(BHT-1) MIMBF 4

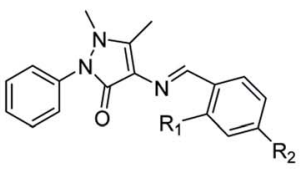

AAPX

Scheme 1 The structures of the related multifunctional additives and Schiff base compounds.

structure similar to Boranil complexes. ${ }^{34,35}$ The antioxidation and antiwear performances of the difluoroboron derivatives of SPD antioxidants as multifunctional additives were evaluated and discussed. To our delight, compared with the traditional ZDDP and the commercial antioxidant diphenylamine (DPA), the selected additive (E)-4-((3-(tert-butyl)-2-((difluoroboranyl)oxy)-5((octylthio)methyl)benzy-lidene)amino)- $N$-phenylaniline (difluoroboron derivative 4a) has better wear resistance and oxidation resistance. As far as we know, this is the first time that boron, fluorine and diphenylamine antioxidants SPD have been combined to form a new non-phosphorus and non-metal compound as a potential multifunctional additive for lubricant.

\section{Materials and experimental section}

\subsection{Materials}

Solvents, reagents and DPA were bought from commercial sources. Polyisobutylene succinimide dispersant (PIBSI) was prepared according to the patent. ${ }^{36}$ And T203 (zinc diisooctyldithiophosphate) was obtained as a gift and chosen to represent ZDDP. Commercial mineral oil $150 \mathrm{~N}$ was purchased from China National Offshore Oil Corporation. The physicochemical properties of T203 and 150N are listed in Table 1.

\subsection{Characterization}

All NMR spectra $\left({ }^{1} \mathrm{H},{ }^{13} \mathrm{C},{ }^{11} \mathrm{~B},{ }^{19} \mathrm{~F}\right)$ were recorded on Bruker AVANCE-400 $\mathrm{MHz}$ spectrometer at room temperature. High resolution mass spectra (HRMS) and element contents were analyzed by UPLC-Q-TOF mass spectrometer (AB Sciex TripleTOF
4600 system) and ICP-OES (SPECTRO ARCOS), respectively. The surface features and energy dispersive X-ray spectroscopy (EDS) of the worn scars were probed by scanning electron microscope (SEM) measurements (EVO18, Zeiss, Germany). The results of Xray photoelectron spectroscopy (XPS) were acquired on imaging photoelectron spectrometer (AXIS ULTRA).

\subsection{Synthesis and characterization of the compounds}

The synthesis process is shown in Scheme 2 and ESI Section S1.1.†

2.3.1. Synthesis of $(E)-2-($ tert-butyl)-4-((octylthio)methyl)-6(((4-(phenylamino)phenyl)imi-no)methyl)phenol (Schiff base 3a). Schiff base 3a as an antioxidant has been synthesized and studied in our previous works. ${ }^{29}$ As an important reaction intermediate and reference material in this study, it was synthesized according to general procedure I of Scheme 2 and ESI Section S1.1.†

Table 1 Properties of T203 and 150N

\begin{tabular}{|c|c|c|}
\hline Item & $\mathrm{T} 203$ & $150 \mathrm{~N}$ \\
\hline Kinematic viscosity $\left(40^{\circ} \mathrm{C}\right), \mathrm{mm}^{2} \mathrm{~s}^{-1}$ & - & 27.9 \\
\hline Kinematic viscosity $\left(100^{\circ} \mathrm{C}\right), \mathrm{mm}^{2} \mathrm{~s}^{-1}$ & - & 5.2 \\
\hline Flash point, ${ }^{\circ} \mathrm{C}$ & $>190$ & 238.1 \\
\hline Water content, wt $\%$ & 0.03 & 0.0073 \\
\hline Sulfur content, wt $\%$ & 15.04 & $<0.0001$ \\
\hline Phosphorus content, wt $\%$ & 7.61 & - \\
\hline Zinc content, \% & 9.02 & - \\
\hline Density, $20^{\circ} \mathrm{C}, \mathrm{kg} \mathrm{m}^{-3}$ & 1096.1 & 840 \\
\hline
\end{tabular}



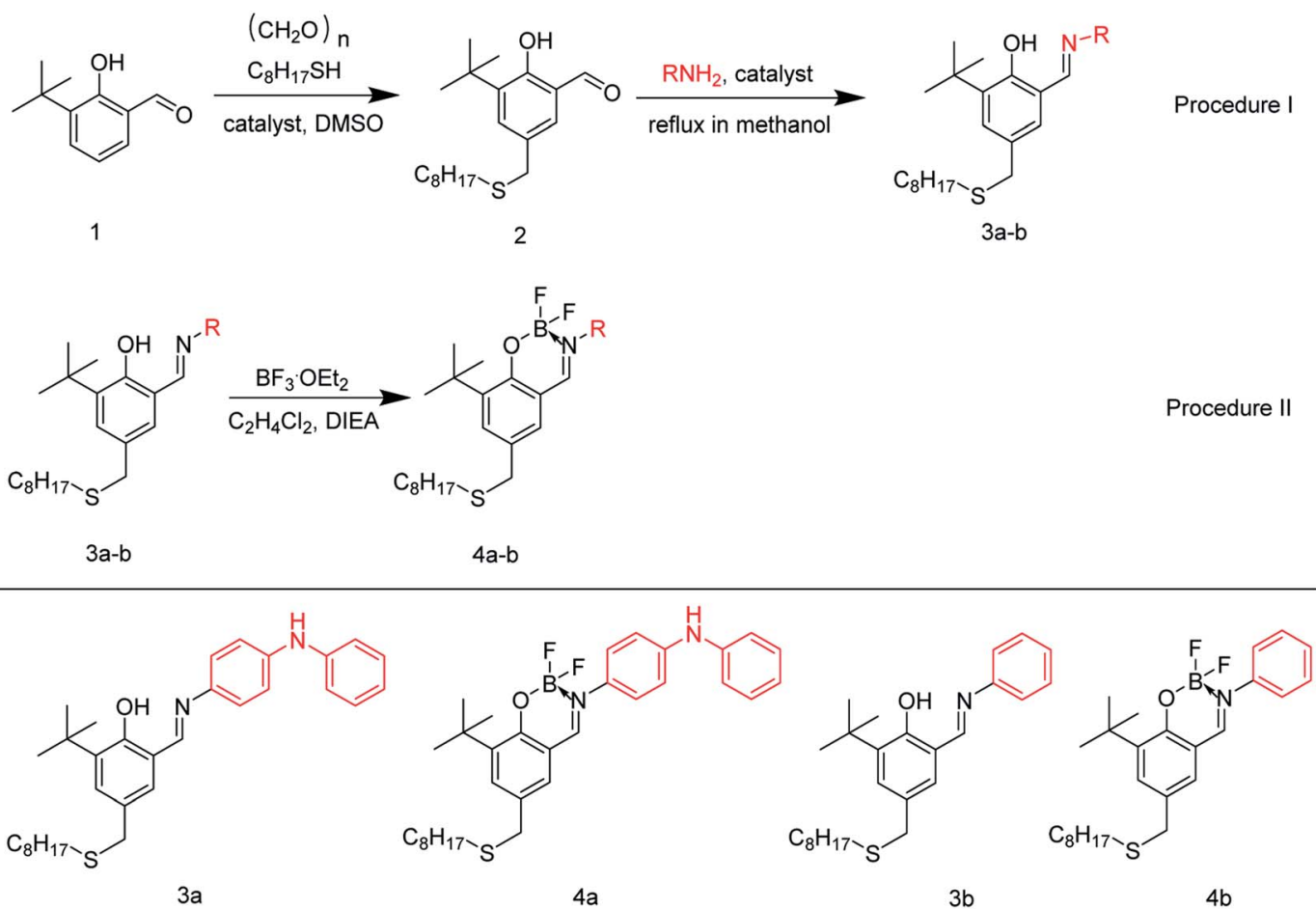

3a

$4 a$

$4 b$

Scheme 2 Synthesis processes of Schiff bases and difluoroboron derivatives.

2.3.2. Synthesis of $(E)-4-((3-($ tert-butyl)-2-((difluoroboranyl) oxy)-5-((octylthio)methyl)ben-zylidene)amino)- $N$-phenylaniline (difluoroboron derivative 4a). The synthesis follows general procedure II of Scheme 2 and ESI Section S1.1. $\dagger$ Starting material: Schiff base 3a. Product: yellow solid. Isolated yield: $85 \%$ (3 g). ${ }^{1} \mathrm{H}$ NMR (Fig. S1, $\left.\dagger 400 \mathrm{MHz}, \mathrm{DMSO}\right) \delta 9.05(\mathrm{~s}, 1 \mathrm{H}$ ), $8.59(\mathrm{~s}, 1 \mathrm{H}), 7.75-6.76(\mathrm{~m}, 11 \mathrm{H}), 3.74(\mathrm{~s}, 2 \mathrm{H}), 2.42(\mathrm{t}, J=7.2 \mathrm{~Hz}$, $2 \mathrm{H}), 1.55-1.13(\mathrm{~m}, 21 \mathrm{H}), 0.84(\mathrm{t}, J=6.5 \mathrm{~Hz}, 3 \mathrm{H}) .{ }^{13} \mathrm{C} \mathrm{NMR}$ (Fig. S2,† $101 \mathrm{MHz}, \mathrm{DMSO}) \delta 163.72$ (s), 156.25 (s), 144.97 (s), 142.74 (s), 138.51 (s), 136.02 (s), 133.89 (s), 131.10 (s), 130.45 (s), 129.76 (s), 124.81 (s), 121.33 (s), 118.42 (s), 116.92 (s), 116.34 (s), $34.96(\mathrm{~d}, J=2.4 \mathrm{~Hz}$ ), 31.69 (s), 31.13 (s), 29.50 (s), 29.25 (s), 29.08 (s), 29.02 (s), 28.70 (s), 22.52 (s), 14.37 (s). ${ }^{11}$ B NMR (Fig. S3,† 128 MHz, DMSO) $\delta 94.33$ (s). ${ }^{19}$ F NMR (Fig. S4,† 377 MHz, DMSO) $\delta-133.77$ (d, $J=23.8 \mathrm{~Hz}$ ). HRMS (Fig. S5 $\dagger$ ) found for $\mathrm{C}_{32} \mathrm{H}_{41^{-}}$ $\mathrm{BF}_{2} \mathrm{~N}_{2} \mathrm{OS}[\mathrm{M}-\mathrm{H}]^{-}:$549.3001, calcd: 549.2997. Elemental analysis, S: $5.57 \%$ (calcd: $5.82 \%$ ); B: $1.86 \%$ (calcd: $1.96 \%$ ). The sulfur content of difluoroboron derivative $\mathbf{4 a}$ is lower than that of ZDDP (e.g. T203 is 15\%).

2.3.3. Synthesis of (E)-1-(3-(tert-butyl)-2-((difluoroboranyl) oxy)-5-((octylthio)methyl)phen-yl)- $N$-phenylmethanimine

(difluoroboron derivative $\mathbf{4 b}$ ). Schiff base $\mathbf{3 b}$ was synthesized by substituting $p$-aminodiphenylamine with aniline in accordance with general procedure I and ESI Section S1. $\dagger$ Then difluoroboron derivative $\mathbf{4 b}$ was obtained by general procedure II and ESI Section S1.1. $\dagger$ Product: yellow oil. Isolated yield: $80 \%$ (2 g). ${ }^{1} \mathrm{H}$ NMR (Fig. S6, $\uparrow 400 \mathrm{MHz}$, DMSO) $\delta 9.14(\mathrm{~s}, 1 \mathrm{H}), 7.80-7.37(\mathrm{~m}$, $7 \mathrm{H}), 3.75(\mathrm{~s}, 2 \mathrm{H}), 2.42(\mathrm{t}, J=7.3 \mathrm{~Hz}, 2 \mathrm{H}), 1.61-1.10(\mathrm{~m}, 21 \mathrm{H})$, $0.84(\mathrm{t}, J=6.7 \mathrm{~Hz}, 3 \mathrm{H}) .{ }^{13} \mathrm{C} \mathrm{NMR}$ (Fig. S7, $\left.\dagger 101 \mathrm{MHz}, \mathrm{DMSO}\right)$ $\delta 166.91$ (s), 156.73 (s), 142.48 (s), 138.65 (s), 136.80 (s), 131.55 (s), 130.64 (s), 129.91 (s), 129.37 (s), 124.03 (s), 116.67 (s), 35.01 (s), $34.83(\mathrm{~s}), 31.69(\mathrm{~s}), 31.07(\mathrm{~s}), 29.48$ (s), 29.22 (s), 29.07 (s), 29.01 (s), 28.68 (s), 22.51 (s), 14.38 (s). ${ }^{11}$ B NMR (Fig. S8, $\dagger 128$ MHz, DMSO) $\delta 0.77$ (s). ${ }^{19}$ F NMR (Fig. S9, $† 377 \mathrm{MHz}$, DMSO) $\delta-133.24$ (d, $J=26.2 \mathrm{~Hz}$ ). HRMS (Fig. S10 $\dagger$ ), calcd for $\mathrm{C}_{26^{-}}$ $\mathrm{H}_{36} \mathrm{BF}_{2} \mathrm{NOS} \mathrm{M} \mathrm{M}^{-}$: 459.2579, found 459.2603. Elemental contents, S: $7.03 \%$ (calcd: $6.98 \%$ ); B: $2.40 \%$ (calcd: $2.35 \%$ ).

\subsection{Tribological test}

The antiwear capacities, last nonseizure loads ( $P_{\mathrm{B}}$ values) and welding loads ( $P_{\mathrm{D}}$ values) were evaluated on Tianji MS-10A fourball test machine. And all steel balls are made of GCr15 material with hardness of 59-61 HRC, surface roughness of less than $0.032 \mu \mathrm{m}$ and ball diameter of $12.7 \mathrm{~mm}$. The extreme pressure properties $\left(P_{\mathrm{B}}\right.$ and $P_{\mathrm{D}}$ ) of lubricants were evaluated by the national standard method GB/T 3142-82 (similar to ASTM D2783) at $1450 \mathrm{rpm}$ and room temperature for 10 seconds. The general test conditions of antiwear capacities are as follows: test temperature, $75{ }^{\circ} \mathrm{C}$; test duration, $60 \mathrm{~min}$; test rotation rate, $1200 \mathrm{rpm}$. All results were repeated at least twice. The wear degree is expressed by the mean wear scar diameter (WSD) and the mean wear volume (WV) of the three stationary balls. After tests, the WSD was obtained by measuring the wear scar diameter of three stationary balls on the microscope and measuring device of the four-ball tester. The WV was calculated by the following equation: ${ }^{37}$

$$
\mathrm{WV}=\left(\frac{\pi h}{6}\right)\left(\frac{3 d^{2}}{4}+h^{2}\right)
$$

where 


$$
h=r-\sqrt{r^{2}-\frac{d^{2}}{4}}
$$

$d$ equals the value of WSD and $r(6.35 \mathrm{~mm})$ is the radius of the steel ball.

\subsection{Antioxidation behavior analysis}

Pressure differential scanning calorimetry (PDSC, NETZSCH DSC 204, Germany) can be used to determine the oxidation induction time (OIT) of lubricants to quickly evaluate their antioxidation property. The experimental process and method can be referred to our previous literatures. ${ }^{\mathbf{2 8 , 2 9}}$ And in this paper, PDSC tests of different lubricants were carried out in the isothermal mode at $180{ }^{\circ} \mathrm{C}$ and 500 psi oxygen pressure.

\section{Results and discussion}

\subsection{Selection of base oil}

In order to increase the solubility of additives in $150 \mathrm{~N}$ and simulate the formulations of commercial lubricants, $150 \mathrm{~N}$ containing $4 \mathrm{wt} \%$ dispersant PIBSI (PIBSI-0.04-150N) was selected as the base oil. ${ }^{38}$ The main structure of dispersant PIBSI is shown in the following structure (a). And the following tests were carried out in the base oil (PIBSI-0.04-150N).

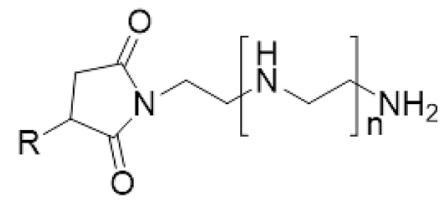

(a)

\subsection{Antioxidation behavior}

As shown in Fig. 1, the antioxidation capacity of different additives in base oil was rapidly and accurately evaluated under the isothermal mode at $180{ }^{\circ} \mathrm{C}$ and 500 psi oxygen pressure. Due to the interaction between dispersant and ZDDP in base oil, ${ }^{39}$ the OIT of ZDDP in base oil (PIBSI-0.04-150N) is lower than that

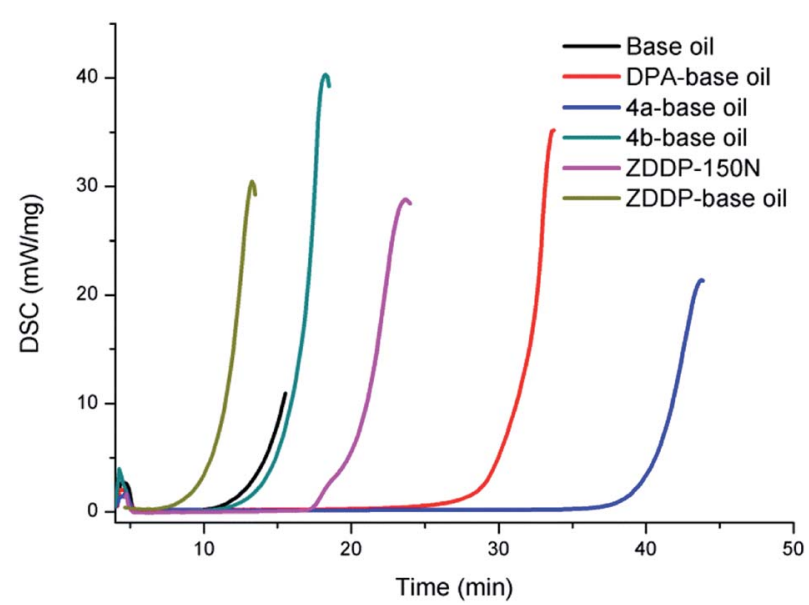

Fig. 1 Antioxidation response of different additives $\left(5 \mu \mathrm{mol} \mathrm{g}{ }^{-1}\right)$ in base oil. in $150 \mathrm{~N}$ (15.6 min). Interestingly, compared with base oil and base oil containing ZDDP, the OIT of base oil containing difluoroboron derivative $\mathbf{4 a}$ increased by 2.25 and 4.76 times, respectively. Compared with DPA, difluoroboron derivative 4a exhibits superior antioxidation capacity, and its OIT increased by $32.7 \%$. Furthermore, as expected, difluoroboron derivative 4b almost has no effect on the antioxidation capacity of base oil. The above results of the comparisons among compounds $\mathbf{4 a}, \mathbf{4 b}$ and DPA show that diphenylamine was the key functional group of antioxidation property. And difluoroboron derivative 4a has better antioxidation capacity than DPA, which may be the result of the intramolecular synergism between arylamines and sulfides, which is consistent with previous research results. ${ }^{29,40}$

\subsection{Extreme pressure performance}

In order to discuss the extreme pressure properties of additive and the strength of oil film, the last nonseizure loads ( $P_{\mathrm{B}}$ values) and welding loads ( $P_{\mathrm{D}}$ values) were evaluated by the national standard method GB/T 3142-82 (similar to ASTM D2783), as shown in Fig. 2. The same $P_{\mathrm{D}}$ value means that additive $4 \mathrm{a}$ has the same extreme pressure working ability as base oil. The $P_{\mathrm{B}}$ value of difluoroboron derivative $4 \mathrm{a}$ is $804 \mathrm{~N}$, which is greater than $510 \mathrm{~N}$ of base oil, indicating that the oil film strength of additive is higher than that of base oil. It is clearly concluded that the strength of base oil film can be significantly improved by adding difluoroboron derivative $\mathbf{4 a}$.

\subsection{Antiwear performances}

3.4.1. Effects of additive concentration. Initially, the antiwear performances of base oil (PIBSI-0.04-150N) with different additive concentrations were investigated by four-ball test machine under $490 \mathrm{~N}$ and general test conditions. The WSD changes of the novel difluoroboron derivative $4 \mathbf{a}$ at different concentrations in the base oil are shown in Fig. 3. Without any additive, the WSD of base oil is as high as $0.715 \mathrm{~mm}$. Adding 2.5 $\mu \mathrm{mol} \mathrm{g}^{-1}$ borated Schiff base $4 \mathrm{a}$ to the base oil can reduce the WSD value to $0.625 \mathrm{~mm}$. The maximum decrease of WSD is

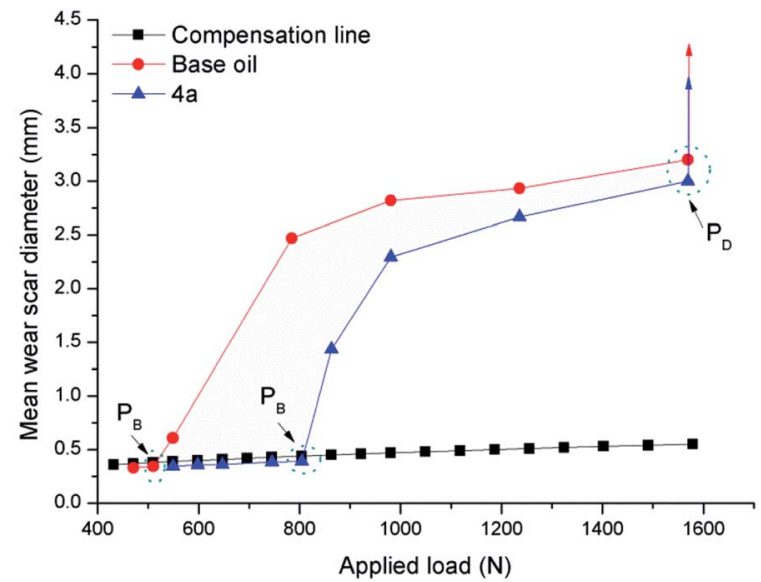

Fig. 2 The plot of $P_{\mathrm{B}}$ and $P_{\mathrm{D}}$ values for $5 \mu \mathrm{mol} \mathrm{g} \mathrm{g}^{-1}$ difluoroboron derivative $4 \mathrm{a}$ and base oil. 
$30.2 \%$ at the concentration of $5 \mu \mathrm{mol} \mathrm{g}{ }^{-1}$, but further increase of additive concentration to 7.5 and $10 \mu \mathrm{mol} \mathrm{g}{ }^{-1}$ will increase the value of WSD, which means higher additive content would not help to improve the antiwear property. The results can be explained as follows: without additives, PIBSI is adsorbed on the steel surface to form a weak oil film. After adding the difluoroborane derivative $4 a$ to the base oil, the PIBSI adsorption film was replaced by additives with strong polar surface adsorption ability. With the increase of additive concentration, the PIBSI adsorptive film was gradually replaced by additives. When the additive concentration is $5 \mu \mathrm{mol} \mathrm{g}{ }^{-1}$, the best additive adsorptive film strength and the best anti-wear effect of the lubricant formulation are obtained. However, when the concentration of additive is more than $7.5 \mu \mathrm{mol} \mathrm{g}^{-1}$, the adsorptive film of lubricant may be dominated by additives. In this case, because of the high concentration, the base oil (including PIBSI) will compete with the additives to adsorb to the metal surface, resulting in the destruction of the adsorptive film of the additives and the reduction of the wear resistance of the lubricants. ${ }^{41-43}$ Considering the best wear resistance at $5 \mu \mathrm{mol} \mathrm{g}{ }^{-1}$

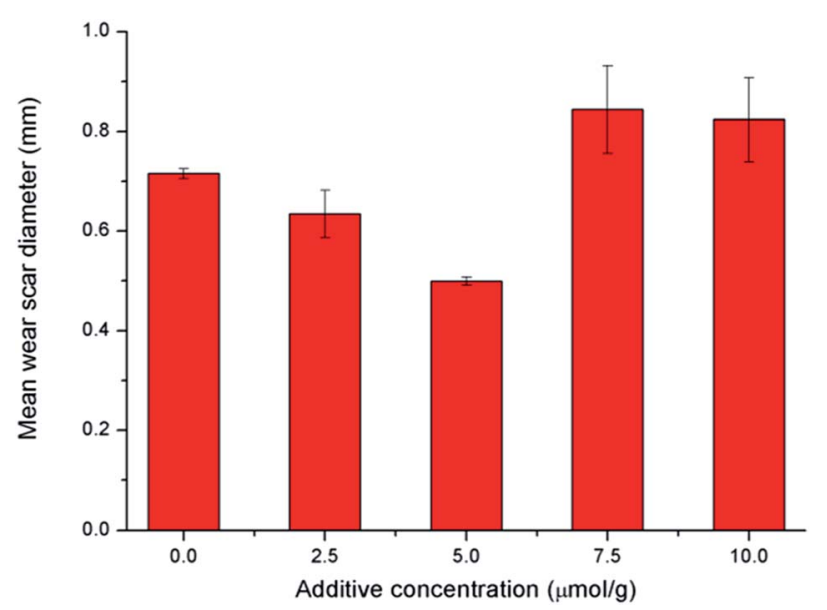

Fig. 3 Variation of the WSD for difluoroboron derivative 4a at different concentrations in base oil. concentration, all the following antiwear tests for other additives were carried out under that concentration.

3.4.2. Effects of applied load. As shown in Fig. 4a, the effect of applied load on antiwear performance of difluoroboron derivative 4a was discussed. Without any additive, the WSD of the base oil increases with the increase of applied load. For the 5 $\mu \mathrm{mol} \mathrm{g}{ }^{-1}$ difluoroboron derivative 4 a, the WSD remained stable under the load less than $588 \mathrm{~N}$. And when the applied load is $490 \mathrm{~N}$, difluoroboron derivative $4 \mathrm{a}$ obtained the best antiwear performance with WSD of $0.499 \mathrm{~mm}$. In order to explain the sudden increase of WSD at $588 \mathrm{~N}$, the friction coefficient curve of difluoroboron derivative $4 \mathrm{a}$ under $588 \mathrm{~N}$ is shown in Fig. $4 \mathrm{~b}$. The two spikes of friction coefficient curve of difluoroboron derivative $4 \mathrm{a}$ indicate that the long wear under $588 \mathrm{~N}$ at $75{ }^{\circ} \mathrm{C}$ destroys the additive adsorption film, which results in the abrupt increase in WSD. For base oil, the spike at the beginning of the test indicates that the adsorption film of base oil is easily destroyed under $588 \mathrm{~N}$, which corresponds to the $P_{\mathrm{B}}$ results of base oil. Base on the change of antiwear performance under different applied load, $490 \mathrm{~N}$ is the selected applied load for the antiwear performance tests.

3.4.3. Antiwear performance of different additives. Fig. $5 \mathrm{a}$ shows the variation of the friction coefficient of steel balls, which were lubricated with the base oil (PIBSI-0.04-150N) containing different additives under $490 \mathrm{~N}$ and general test conditions. Due to the surface adsorption ability of the nitrogen atom in PIBSI, the friction coefficient of base oil is not less than that of $5 \mu \mathrm{mol} \mathrm{g}{ }^{-1}$ additives in base oil. The adsorption and corrosion of the fluorine make the surface of steel ball rough and increase the friction coefficients of difluoroboron derivatives $\mathbf{4 a}$ and $\mathbf{4 b}$.

The antiwear performance is estimated in terms of the WSD and WV (Fig. 5b), notably, compared with the commercial ZDDP, difluoroboron derivative 4 a presents a better antiwear property with reduction of $22.8 \%$ and $64.4 \%$ on WSD and WV, respectively. And compared with base oil, the WSD (or WV) of additive $3 \mathbf{a}, \mathbf{4 a}$, and $\mathbf{4 b}$ decreased by $12.7 \%$ (or $41.9 \%$ ), $30.2 \%$ (or $76.3 \%$ ) and $30.8 \%$ (or $77.1 \%$ ), respectively. Moreover, compared
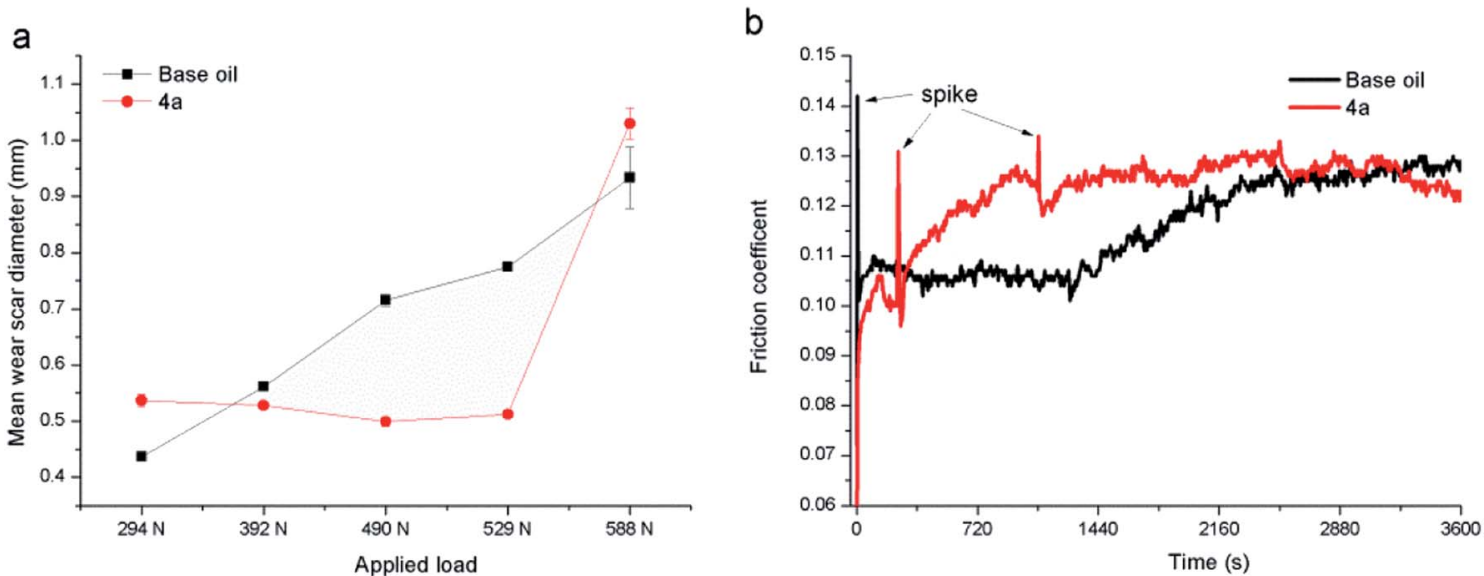

Fig. 4 (a) Variation of the WSD for difluoroboron derivative $4 a$ and base oil under different applied loads; and (b) friction coefficient under the load of $588 \mathrm{~N}$. 

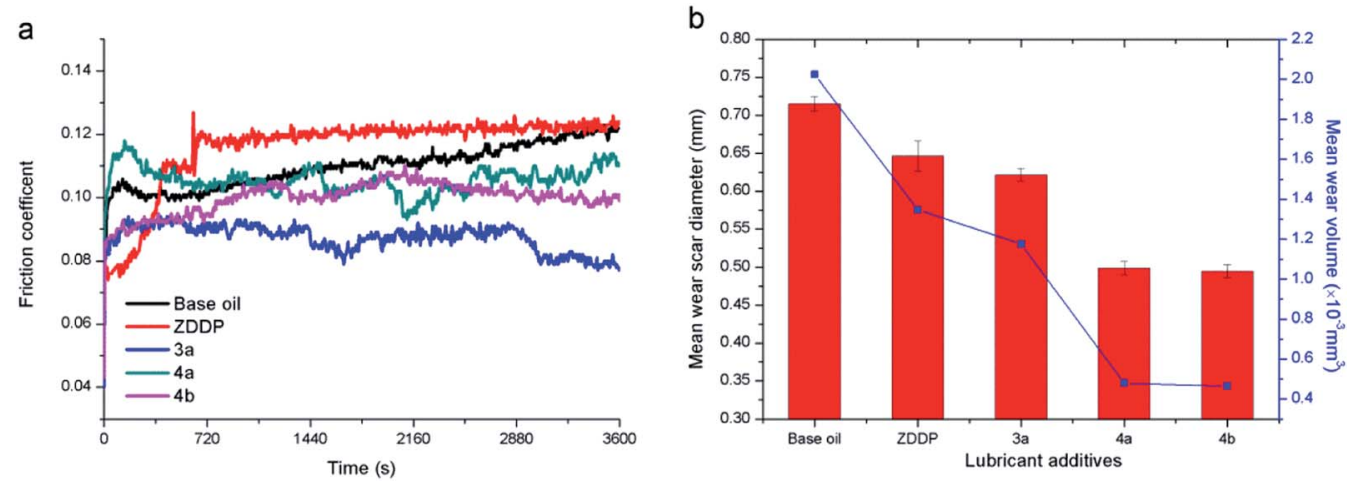

Fig. 5 Variation of the friction coefficient (a) and WSD/WV (b) for different kinds of additives in base oil, additive concentration in base oil is 5 $\mu \mathrm{mol} \mathrm{g}{ }^{-1}$.

with Schiff base 3a, the compound $\mathbf{4 a}$ exhibits excellent antiwear property with a reduction of WSD and WV about $20.1 \%$ and $59.2 \%$, respectively. This strong wear resistance means that the existence of boron and fluorine elements can largely improve the antiwear performance. In order to discuss the effects of diphenylamine and boron and fluorine elements functional group, comparative experiments of difluoroboron derivative $\mathbf{4 b}$ were carried out. On the basis of the results, difluoroboron derivative $\mathbf{4 a}$ and $\mathbf{4 b}$ have good antiwear ability because of the influence of fluorine and boron, but have nothing to do with the structure of diphenylamine. The enhancement of the antiwear capability may be due to the participation of the boron and fluorine elements in tribological process and tribochemistry. ${ }^{14,33,44,45}$

\subsection{Worn surface analysis}

For better understanding the morphology and tribochemistry of worn surfaces, SEM and EDS were employed. Obviously, the metal surfaces (Fig. 6a and c) of the ball lubricated only with base oil display obvious larger wear scars and deeper furrows than those lubricated with additive 3a (Fig. 7a and c) and difluoroboron derivative 4a (Fig. 8a and c). The results show that the wear and damage of the ball lubricated only with base oil are serious during the tribological process. Compared with base oil, it can be clearly seen from the elemental mapping that Schiff base 3a is adsorbed onto the worn surface due to the surface adsorption properties of sulfur element, as shown in Fig. 7d-f. Corresponding to the better antifriction effect discussed above, Schiff base 3a lubricating ball has smooth wear scar (Fig. 7c) because of additive's strong surface adsorption and antiwear properties. Although the difluoroborane derivative 4a lubricating ball has grooves on the wear surface (Fig. 8c), the wear scar is smaller than that of the base oil and Schiff base 3a, and the wear scuffing is not sharp. In addition, in Fig. 8b, the obviously detection of B (14.46 atomic\%) and F (9.07 atomic\%) indicates that the strong polar boron and fluorine elements of additive $\mathbf{4 a}$ are transferred to the interface and formed a protective layer. Element mapping Fig. $8 \mathrm{e}$ and $\mathrm{f}$ show that $\mathrm{B}$ and $\mathrm{F}$ atoms are involved in the formation of scaly debris on wear scars, which provide intuitive evidence for the speculation of the antiwear mechanism discussed earlier. And the same wear mechanism and results are shown in the SEM images of

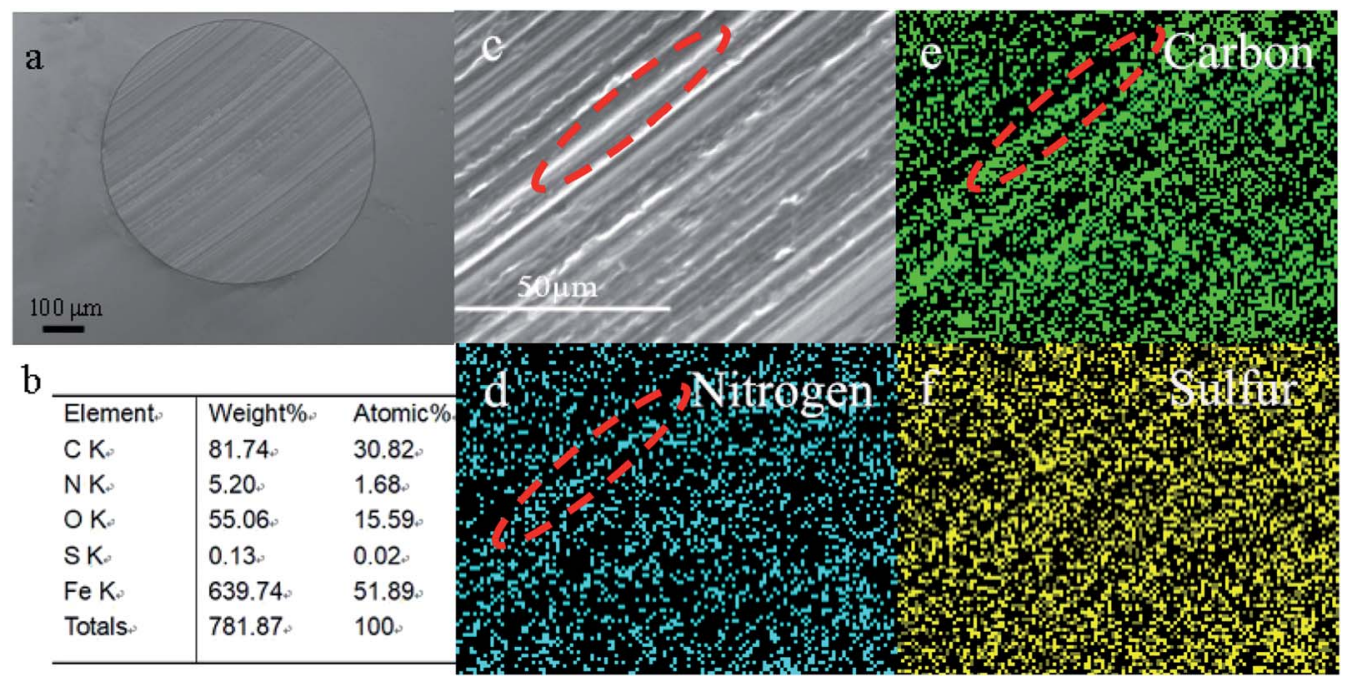

Fig. 6 SEM images ( $a$ and c), elemental content (b) and elemental mapping ( $d-f)$ of the rubbing surfaces, lubricated with base oil. 


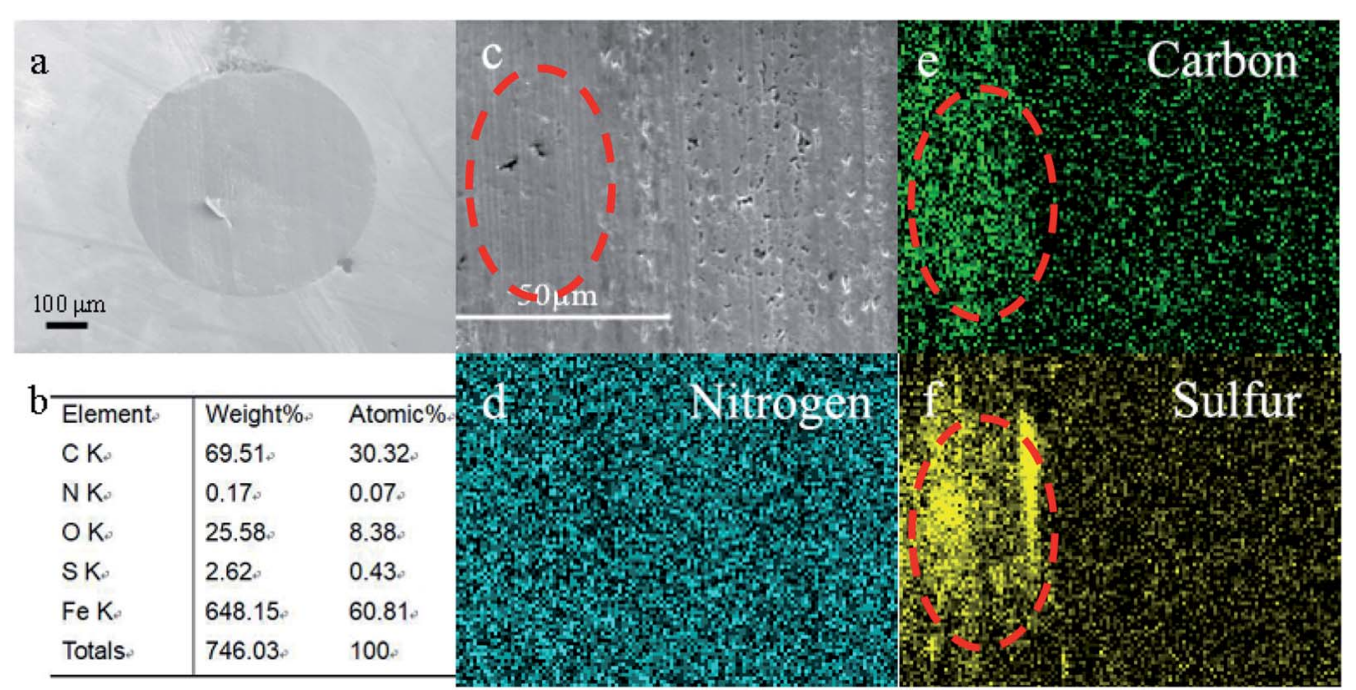

Fig. 7 SEM images ( $a$ and c), elemental content (b) and elemental mapping ( $d-f)$ of the rubbing surfaces, lubricated with Schiff base 3a

difluoroborane derivative $\mathbf{4 b}$ in Fig. S11 and S12. $\dagger$ It is speculated that the abrasives are formed by the exfoliation of hard compounds, which are generated by the tribochemical interaction of boron and fluorine with iron.

In order to further understand the lubrication mechanism of difluoroboron derivative 4a in base oil, XPS was used to investigate the compositions of the worn surfaces. As shown in Fig. 9, the $\mathrm{B} 1 \mathrm{~s}$ peak at $191.6 \mathrm{eV}$ is assigned to $\mathrm{B}_{2} \mathrm{O}_{3} / \mathrm{Fe}-\mathrm{O}-\mathrm{B}$, corresponding to the $\mathrm{O} 1 \mathrm{~s}$ at $533.0 \mathrm{eV}$, which suggests that the difluoroboron derivative $\mathbf{4 a}$ is degraded and reacted with oxygen during the friction process. ${ }^{16,41,46,47}$ Fluorine peak at about $684.3 \mathrm{eV}$ corresponds to iron fluorides. The Fe 2p3/2 spectra exhibit photoelectron intensity at a binding energy consistent with $\mathrm{FeF}_{3}$ and $\mathrm{Fe}_{2} \mathrm{O}_{3}$ at about $713.7 \mathrm{eV}$ and $710.5 \mathrm{eV}$, respectively. ${ }^{33,47}$ The peak of $\mathrm{N} 1 \mathrm{~s}$ at $399.8 \mathrm{eV}$ indicates the existence of organic nitrogen compound. ${ }^{16,41,48}$ The $O 1$ s binding energy of $529.7 \mathrm{eV}$ and $531.6 \mathrm{eV}$ corresponds to $\mathrm{FeO}$ and $\mathrm{C}-\mathrm{O}$, respectively. ${ }^{42,49}$ The composition of the boundary film, including inorganic and organic compounds, effectively improves the antiwear ability, and further confirms the participation of difluoroboron derivative $\mathbf{4 a}$ in tribochemical reaction.

Base on the above results and discussions, the method of oil film formation containing difluoroboron derivative $\mathbf{4 a}$ has been speculated. Without additives, PIBSI adsorbs on the steel surface to form a weak oil film. When the additive is added to the base oil at a suitable concentration $\left(5 \mu \mathrm{mol} \mathrm{g}^{-1}\right)$, the strong polar adsorption ability of additive makes the replacement of PIBSI happens and forms a tough hybrid oil film. And then, high speed (1200 rpm) and high temperature of the contact area (higher than $150{ }^{\circ} \mathrm{C}$ ) make the additive decompose and react with iron during the antiwear process..$^{50,51}$ Finally, the persistent boundary film consisting of $\mathrm{B}_{2} \mathrm{O}_{3}, \mathrm{Fe}_{2} \mathrm{O}_{3}$, N-containing organic compounds and iron fluoride is formed.

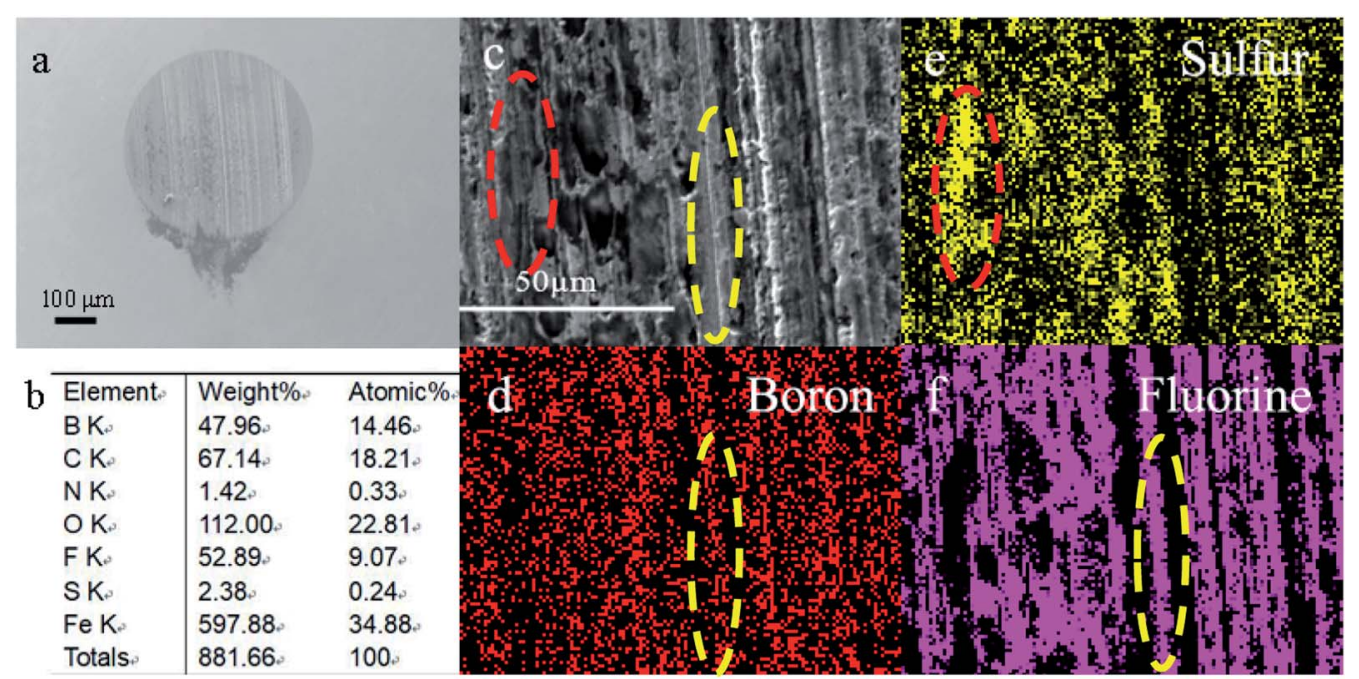

Fig. 8 SEM images ( $a$ and $c$ ), elemental content $(b)$ and elemental mapping $(d-f)$ of the rubbing surfaces, lubricated with difluoroboron derivative $4 a$. 

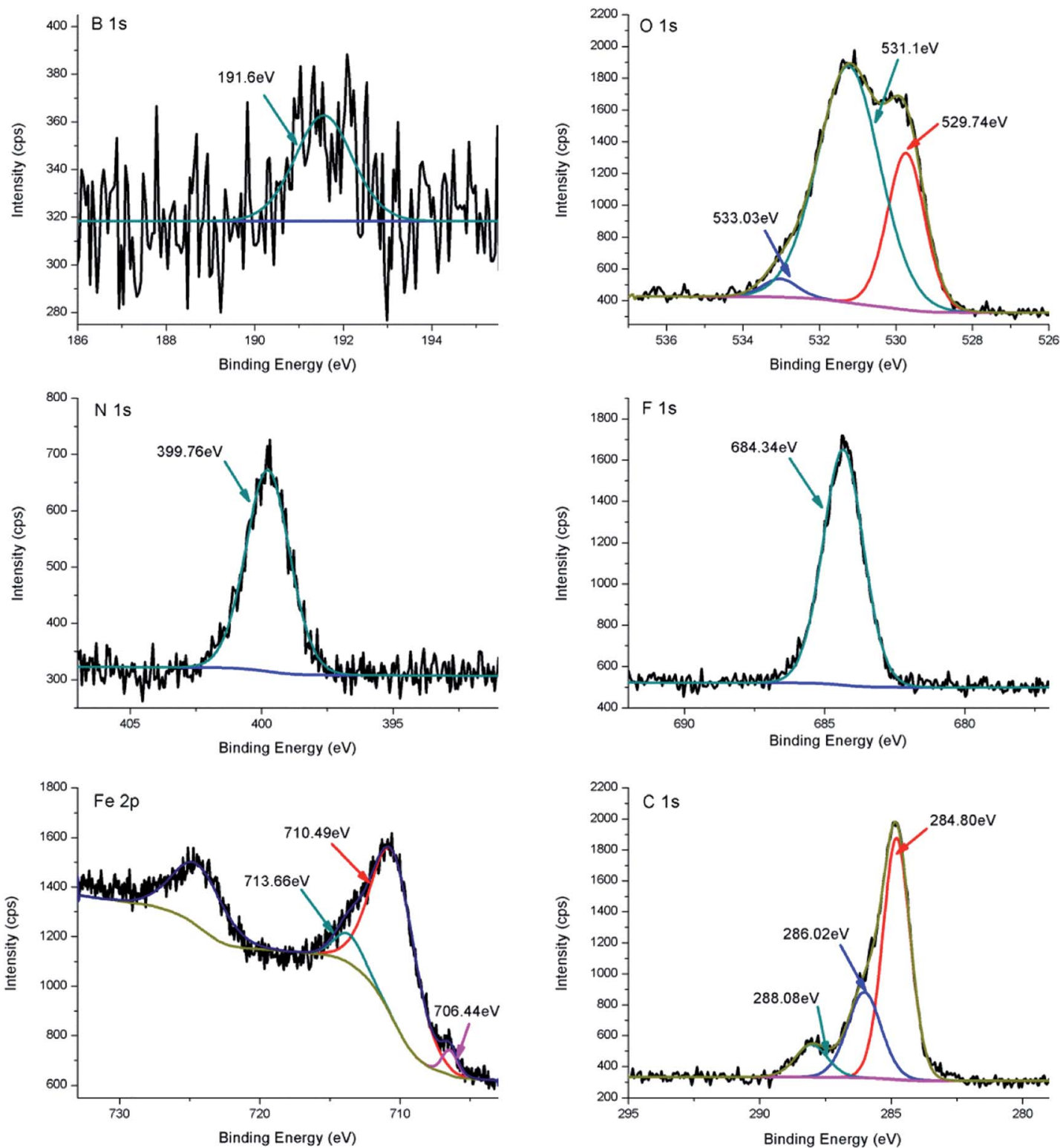

Fig. 9 XPS spectra of worn surfaces on the steel balls were lubricated by $5 \mu \mathrm{mol} \mathrm{g}^{-1}$ of difluoroboron derivative 4 a in base oil.

\section{Conclusions}

Several metal-free and phosphorus-free compounds were synthesized, characterized and evaluated as lubricant additives. As a new multifunctional lubricant additive by modifying diphenylamine, the antioxidation, extreme pressure properties and antiwear properties of difluoroboron derivative $4 \mathbf{a}$ were evaluated. The additive 4 a shows better antioxidation performance than base oil, traditional antioxidant DPA and ZDDP. And diphenylamine is the main source of antioxidation property of difluoroboron derivative 4a. Addition of difluoroboron derivative $4 a$ can significantly improves the extreme pressure performance of base oil. For antiwear test, the concentration of $5 \mu \mathrm{mol} \mathrm{g}{ }^{-1}$ and $490 \mathrm{~N}$ was selected as additive concentration and applied load respectively. In addition, under the selected test conditions, the antiwear property of difluoroboron derivative $\mathbf{4 a}$ is better, and its mean wear volume is reduced by $76.3 \%, 64.4 \%$ and $59.2 \%$ compared to base oil, ZDDP and Schiff base 3a, respectively. On the basis of the results, difluoroboron derivative $\mathbf{4 a}$ and $\mathbf{4 b}$ have good antiwear ability because of the influence of fluorine and boron, but have nothing to do with the structure of diphenylamine. The wear mechanism can be defined as abrasive wear according to the SEM and EDS results of the worn surfaces. XPS results show that the tribofilm is composed of $\mathrm{B}_{2} \mathrm{O}_{3}$, $\mathrm{Fe}_{2} \mathrm{O}_{3}$, N-containing organic compounds and iron fluoride such as $\mathrm{FeF}_{3}$. The composition of tribofilm reveals that difluoroboron derivative $\mathbf{4 a}$ is involved in complicated tribochemical reactions and effectively improves the antiwear capacity. Therefore, as a novel metal-free and phosphorus-free multifunctional additive, the difluoroboron derivative $\mathbf{4 a}$ has the potential application in lubricant. 


\section{Conflicts of interest}

There are no conflicts to declare.

\section{Acknowledgements}

This research was supported by National Natural Science Foundation of China (Grand No. 21606247).

\section{References}

1 N. J. Mosey, M. H. Müser and T. K. Woo, Science, 2005, 307, 1612-1615.

2 W. Li, Y. Wu, X. Wang and W. Liu, Lubr. Sci., 2011, 23, 363373.

3 J. M. Martin, Tribol. Lett., 1999, 6, 1-8.

4 H. A. Spikes, Tribol. Lett., 2004, 17, 469-489.

5 H. Spikes, Lubr. Sci., 2008, 20, 103-136.

6 J. L. Maurya, V. Jaiswal and R. B. Rastogi, Proc. Inst. Mech. Eng., Part J, 2015, 230, 222-237.

7 W. Li, C. Jiang, M. Chao and X. Wang, ACS Sustainable Chem. Eng., 2014, 2, 798-803.

8 R. B. R. Kalyani and D. Kumar, ACS Sustainable Chem. Eng., 2016, 4, 3420-3428.

9 R. K. Singh, A. Kukrety and A. K. Singh, ACS Sustainable Chem. Eng., 2014, 2, 1959-1967.

10 M. Chao, W. Li, L. Chen and X. Wang, Ind. Eng. Chem. Res., 2015, 54, 6605-6610.

11 G. Biresaw, D. Compton, K. Evans and G. B. Bantchev, Ind. Eng. Chem. Res., 2016, 55, 373-383.

12 G. Biresaw, J. A. Laszlo, K. O. Evans, D. L. Compton and G. B. Bantchev, J. Agric. Food Chem., 2014, 62, 2233-2243.

13 G. Yang, Z. Zhang, G. Li, J. Zhang, L. Yu and P. Zhang, J. Tribol., 2011, 133, 021801.

14 R. B. Choudhary and P. P. Pande, Lubr. Sci., 2010, 14, 211222.

15 L. Wang, H. Wu, D. Zhang, G. Dong, X. Xu and Y. Xie, Tribol. Int., 2018, 121, 21-29.

16 Y. Zhang, T. Cai, W. Shang, L. Sun, D. Liu, D. Tong and S. Liu, Tribol. Int., 2017, 115, 297-306.

17 Y. Zhou and J. Qu, ACS Appl. Mater. Interfaces, 2017, 9, 32093222.

18 S. Shahnazar, S. Bagheri and S. B. Abd Hamid, Int. J. Hydrogen Energy, 2016, 41, 3153-3170.

19 M. Ye, T. Cai, W. Shang, L. Zhao, Y. Zhang, D. Liu and S. Liu, Tribol. Int., 2018, 127, 557-567.

20 M. S. Charoo and M. F. Wani, Lubr. Sci., 2017, 29, 241-254.

21 R. K. Singh, S. Pandey, R. C. Saxena, G. D. Thakre, N. Atray and S. S. Ray, J. Ind. Eng. Chem., 2015, 26, 149-156.

22 R. K. Singh, A. Kukrety, O. P. Sharma, M. K. Poddar, N. Atray, G. D. Thakre and S. S. Ray, Waste Biomass Valorization, 2016, 7, 1437-1445.

23 R. K. Singh, A. Kukrety, A. K. Chatterjee, G. D. Thakre, G. M. Bahuguna, S. Saran, D. K. Adhikari and N. Atray, Ind. Eng. Chem. Res., 2014, 53, 18370-18379.

24 R. K. Singh, S. Pandey, R. C. Saxena, G. D. Thakre, N. Atray and S. S. Ray, New J. Chem., 2015, 39, 5354-5359.
25 Z. He, L. Xiong, F. Xie, M. Shen, S. Han, J. Hu and W. Xu, PLoS One, 2018, 13, e0207267.

26 M. Cai, Y. Liang, F. Zhou and W. Liu, Wear, 2013, 306, 197208.

27 M. Cai, Y. Liang, M. Yao, Y. Xia, F. Zhou and W. Liu, ACS Appl. Mater. Interfaces, 2010, 2, 870-876.

28 S. Yu, J. Feng, T. Cai and S. Liu, Ind. Eng. Chem. Res., 2017, 56, 4196-4204.

29 S. Yu and S. Liu, Eur. J. Org. Chem., 2018, 2018, 381-385.

30 V. Jaiswal, K. Kalyani, R. B. Rastogi and R. Kumar, J. Mater. Chem. A, 2014, 2, 10424-10434.

31 K. Kalyani, V. Jaiswal, R. B. Rastogi and D. Kumar, Proc. Inst. Mech. Eng., Part J, 2016, 231, 357-365.

32 Z. Zheng, G. Shen, Y. Wan, L. Cao, X. Xu, Q. Yue and T. Sun, Wear, 1998, 222, 135-144.

33 G. Gu, Z. Wu, Z. Zhang and F. Qing, Tribol. Int., 2009, 42, 397-402.

34 D. Frath, S. Azizi, G. Ulrich, P. Retailleau and R. Ziessel, Org. Lett., 2011, 13, 3414.

35 J. Dobkowski, P. Wnuk, J. Buczynska, M. Pszona, G. Orzanowska, D. Frath, G. Ulrich, J. Massue, S. Mosquera-Vazquez, E. Vauthey, C. Radzewicz, R. Ziessel and J. Waluk, Chemistry, 2015, 21, 1312-1327.

36 C. Huang and J. T. Loper, US Pat., US2008188385-A1, 2008.

37 D. Berman, A. Erdemir and A. V. Sumant, Carbon, 2013, 59, 167-175.

38 Y. Zhang, X. Zeng, H. Wu, Z. Li, T. Ren and Y. Zhao, Tribol. Lett., 2014, 53, 533-542.

39 M. Shiomi, M. Tokashiki, H. Tomizawa and T. Kuribayashi, Lubr. Sci., 2010, 1, 131-147.

40 J. B. He, H. Shi, Y. Wang and X. L. Gao, Molecules, 2018, 23, 1-8.

41 F. Jin, G. Yang, Y. Peng, S. Zhang, L. Yu and P. Zhang, Lubr. Sci., 2016, 28, 505-519.

42 V. Jaiswal, S. R. Gupta, R. B. Rastogi, R. Kumar and V. P. Singh, J. Mater. Chem. A, 2015, 3, 5092-5109.

43 A. Sammaiah, K. V. Padmaja, S. S. Kaki and R. B. N. Prasad, RSC Adv., 2015, 5, 77538-77544.

44 Y. Shi and J. Dong, Lubr. Sci., 2000, 12, 357-361.

45 R. B. Rastogi, J. L. Maurya and V. Jaiswal, Tribol. Trans., 2013, 56, 592-606.

46 H. Zhongyi, X. Liping, Q. Liang, H. Sheng, C. Aixi, Q. Jianwei and F. Xisheng, Lubr. Sci., 2014, 26, 81-94.

47 D. D. Hawn and B. M. Dekoven, Surf. Interface Anal., 1987, 10, 63-74.

48 G. Yang, J. Zhao, L. Cui, S. Song, S. Zhang, L. Yu and P. Zhang, RSC Adv., 2017, 7, 7944-7953.

49 Y. Liu, P. Liu, L. Che, C. Shu and X. Lu, Chin. Sci. Bull., 2012, 57, 4641-4645.

50 F. Spadaro, A. Rossi, E. Lainé, P. Woodward and N. D. Spencer, Tribol. Lett., 2016, 65, 11.

51 S. Q. A. Rizvi, A comprehensive review of lubricant chemistry, technology, selection, and design, Library of Congress Cataloging-in-Publication Data, ASTM International, Baltimore, 2009. 